\title{
Simulação numérica do fluxo d'água em pavimentos asfálticos compostos por misturas asfálticas com diferentes coeficientes de permeabilidade
}

\author{
Wellington Lorran Gaia Ferreira' ${ }^{1}$, Verônica Teixeira Franco Castelo Branco², Francisco Chagas da Silva Filho ${ }^{3}$
}

\begin{abstract}
Resumo: A água pode atingir o pavimento de diversas formas, como por precipitação ou ascensão capilar. O efeito deletério da água é um dos principais fatores responsáveis pelo desgaste de pavimentos asfálticos. Um parâmetro para examinar a qualidade do pavimento com relação ao escoamento de água é a permeabilidade dos materiais que compõem as diversas camadas da estrutura. Nesse contexto, o presente trabalho tem como objetivo avaliar o padrão de fluxo d’água em pavimentos asfálticos compostos por misturas asfálticas com diferentes coeficientes de permeabilidade ( $k$ ). Para isso, foi utilizado um programa baseado no método dos elementos finitos (MEF) para modelar o fluxo d’água em um perfil hipotético de um sistema em camadas. No total, foram analisadas seis misturas asfálticas com diferentes percentuais de Volume de vazios (Vv): quatro com granulometria densa, sendo duas do tipo Areia Asfáltica - AA (7\% e 9\% de Vv) e duas do tipo Concreto Asfáltico - CA (4\% e 7\% de Vv), e duas com granulometria aberta do tipo Camada Porosa de Atrito - CPA (20\% e 23\% de $\mathrm{Vv}$ ). Os resultados demostram que o padrão de fluxo depende não somente da permeabilidade média do material, mas também da forma como a permeabilidade está distribuída na camada de revestimento.
\end{abstract}

Palavras-chave: pavimentos, misturas asfálticas, permeabilidade, fluxo de água.

\begin{abstract}
The water can reach the pavement in various ways, such as by precipitation or by capillarity. The deleterious effect of water is a major factor responsible for the distresses in asphalt pavements. An important parameter to verify the quality of the pavement with respect to water flow is the material permeability. In this context, this work aims to evaluate the water flow pattern in asphalt pavements composed by different types of asphalt mixes. With this purpose, a finite element program was used to model the water flow in a hypothetical profile of asphalt pavement. Six types of asphalt mixes with different air voids content were analyzed: four with dense gradation, two types of sand asphalt (7\% and 9\% air voids), and two types of asphalt concrete (4\% and $7 \%$ air voids), and two open grade friction course ( $20 \%$ and $23 \%$ air voids). The results show that the flow pattern depends not only on the average permeability of the material, but also on the material permeability distribution.
\end{abstract}

Keywords: pavements, asphalt mixtures, permeability, water flow.

\section{INTRODUÇÃO}

O Brasil apresenta grande parte de seu território sujeito a chuvas intensas, que têm como principais características a curta duração e o grande volume de água precipitado. O acúmulo de água sobre a superfície do pavimento é responsável por problemas em rodovias como a hidroplanagem, que ocorre quando há falta de aderência no contato pneu-pavimento, e o efeito spray de água, que surge com a passagem dos pneus no pavimento molhado.

Um dos principais fatores que controla o desempenho do pavimento é a capacidade do revestimento de impedir que a água permaneça no interior do sistema (Al Omari, 2004). O efeito deletério da água, com relação à camada de revestimento, está relacionado à perda de adesão entre o ligante asfáltico e os agregados (falha adesiva) e à perda de

\footnotetext{
${ }^{1}$ Wellington Lorran Gaia Ferreira, Departamento de Engenharia de Transportes - DET, Engenharia Civil, Universidade Federal do Ceará (UFC). (wlorran@hotmail.com)

2 Verônica Teixeira Franco Castelo Branco, Departamento de

Engenharia de Transportes - DET, Engenharia Civil, Universidade Federal

do Ceará (UFC). (veronica@det.ufc.br)

${ }^{3}$ Francisco Chagas da Silva Filho, Universidade Federal do Ceará UFC. Departamento de Engenharia Hidráulica e Ambiental - DEHA, Engenharia Civil, UFC. (fchagas@ufc.br)
}

Manuscrito recebido em 30/06/2015 e aprovado para publicação em $16 / 08 / 2015$

Este artigo é parte de TRANSPORTES v. 23, n. 3, 2015. ISSN: 2237-1346 (online). DOI: 10.14295/transportes.v23i3.960 coesão dentro do próprio filme de ligante asfáltico (falha coesiva). Esse mecanismo, denominado dano por umidade induzida, pode agravar outras formas de danos, tais como o acúmulo da deformação permanente e o trincamento por fadiga.

A permeabilidade é uma propriedade do material que expressa a capacidade de percolação de um fluido por um meio poroso. Em misturas asfálticas, o fluido em estudo é a água. No Brasil, não há uma metodologia definida para a determinação do coeficiente de permeabilidade $(k)$ de misturas asfálticas. Na literatura, existem vários estudos que propõem métodos para avaliar a permeabilidade nesse tipo de material (Oliveira, 2003; Nascimento, 2005; Souza, 2008; Chaves, 2010). A maioria desses estudos adota como válida a Lei de Darcy.

Nesse contexto, de forma a entender o comportamento do fluxo de água no pavimento, o presente trabalho analisou este fluxo em uma seção hipotética de pavimento asfáltico. O programa Slide 6.0, comumente utilizado para análise de fluxo em materiais granulares (e.g., barragens de terra) foi usado para a análise. Foram avaliadas um total de seis misturas asfálticas, sendo duas do tipo Areia Asfáltica - AA (7\% e 9\% de Volume de vazios - Vv), duas do tipo Concreto Asfáltico - CA (4\% e 7\% de Vv) e duas com granulometria aberta do tipo Camada Porosa de Atrito - CPA (20\% e $23 \%$ de Vv).

O $k$ de cada uma das misturas asfálticas avaliadas (CA, AA e CPA) foi obtido experimentalmente pelo pri- 
meiro autor do presente trabalho. O detalhamento do método utilizado para a determinação do $k$, bem como a análise dos valores obtidos para cada mistura asfáltica está disponível em Ferreira (2013) e em Ferreira e Castelo Branco (2014). Esses valores de $k$ foram utilizados como dados de entrada na análise de fluxo.

\section{FUNDAMENTAÇÃO TEÓRICA}

\subsection{Permeabilidade de Misturas Asfálticas}

Na maioria das rodovias do país, os sistemas de drenagem nem sempre estão preparados para o grande volume de água precipitado nas chuvas. Boa parte dos projetos não prevê a infiltração da água para o interior do pavimento. Desde problemas práticos, como o fenômeno da hidroplanagem, até problemas estruturais, como o agravamento da deformação permanente e do trincamento por fadiga, podem ser causados pelo acúmulo de água nos pavimentos. Dessa forma, é essencial avaliar a permeabilidade da camada de revestimento tentando buscar soluções para evitar o acúmulo de água nessas estruturas.

A permeabilidade de um material poroso é definida como a capacidade deste em transportar um fluido através dos seus vazios quando sujeito à pressão (Al Omari, 2004). O fluido em estudo geralmente é a água, no entanto, existem estudos, como o de Ellis e Schmidt (1960), que usaram o ar sob pressão para avaliar a permeabilidade de misturas asfálticas. A permeabilidade de qualquer material está diretamente relacionada com as características dos componentes que o constituem, bem como com as características do fluido percolante.

Em relação aos materiais que compõem a mistura asfáltica, fatores como a forma dos agregados podem afetar a permeabilidade da mesma. Agregados angulares promovem maior intertravamento e atrito entre si, proporcionando uma estrutura interna mais rígida, diminuindo os espaços vazios no interior do revestimento. Como consequência, estes podem diminuir a permeabilidade da mistura asfáltica por meio da redução dos vazios interconectados no interior do material. Nesse contexto, o modo como os componentes da mistura asfáltica se organizam no interior da estrutura é fundamental para determinar a permeabilidade da mesma, pois aqueles definem o tamanho, a quantidade e a distribuição dos vazios. Segundo Al Omari (2004), além dos materiais constituintes, a permeabilidade de misturas asfálticas é influenciada pelo processo de compactação e por propriedades geométricas do pavimento, como a espessura da camada de revestimento. Segundo o autor, estes fatores alteram a distribuição de vazios em termos de tamanho, de conectividade e de distribuição dos mesmos, afetando a permeabilidade da mistura asfáltica.

\subsection{Fluxo de Água em Misturas Asfálticas}

Entender como ocorre o fluxo d’água no interior de um material poroso é fundamental, pois o padrão de fluxo pode ajudar a prever o comportamento do material quando sujeito à presença de água. Alguns estudos, disponíveis na literatura internacional, simularam o fluxo d’água em pavimentos asfálticos (Masad et al., 2002; Al Omari, 2004; Kutay et al., 2007). Outros estudos, encontrados na literatura nacional, avaliaram o comportamento do fluxo d’água em barragens com núcleo composto por misturas asfálticas (Falcão, 2007; Guimarães, 2012). Falcão (2007) utilizou o programa SEEP/W para simular o comportamento do fluxo d'água em uma barragem com espessura de núcleo de 1,0m de CA com 5,5\% de teor de ligante asfáltico e Vv médio de $2 \%$. Os resultados demonstraram que a barragem com núcleo de CA apresenta valores de vazão da mesma ordem de grandeza se comparados aos valores da mesma barragem com núcleo de solo com largura da base do núcleo maior do que $100 \mathrm{~m}$.

Em pavimentos asfálticos, Masad et al. (2002) utilizaram o programa SEEP/W para verificar o fluxo d'água em uma seção transversal hipotética composta por revestimento e base sob um subleito com propriedades conhecidas. Para que a água possa fluir de um ponto para outro é necessária uma diferença positiva entre a carga total dos dois pontos. Em vista disso, foi gerada uma malha de elementos finitos para obtenção de uma solução numérica com relação ao comportamento da carga total nos diversos pontos do revestimento. A malha incluía 11.422 elementos quadriláteros e triangulares. A seção do pavimento analisada pelos referidos autores é apresentada na Figura 1.

A camada de base e o subleito foram considerados saturados, com valores de $k$ admitidos como constantes $\left(k_{\text {base }}=1,54 \times 10^{-6} \mathrm{~m} / \mathrm{s}\right.$ e $\left.k_{\text {subleito }}=2,75 \times 10^{-8} \mathrm{~m} / \mathrm{s}\right)$. A camada de revestimento foi dividida em quatro subcamadas de 10,4mm de espessura cada, pois a permeabilidade do revestimento asfáltico depende da distribuição dos vazios no interior do material. Para cada subcamada de $10,4 \mathrm{~mm}$, foi admitido um $\mathrm{Vv}$ diferente, e o $k$ foi calculado de acordo com a Equação 1.

$$
\mathrm{k}=\frac{\mathrm{V}_{\mathrm{v}}^{\mathrm{m}}}{\mathrm{c} \times \mathrm{S}_{\mathrm{agg}}^{\mathrm{t}}} \times \frac{\gamma}{\mu}
$$

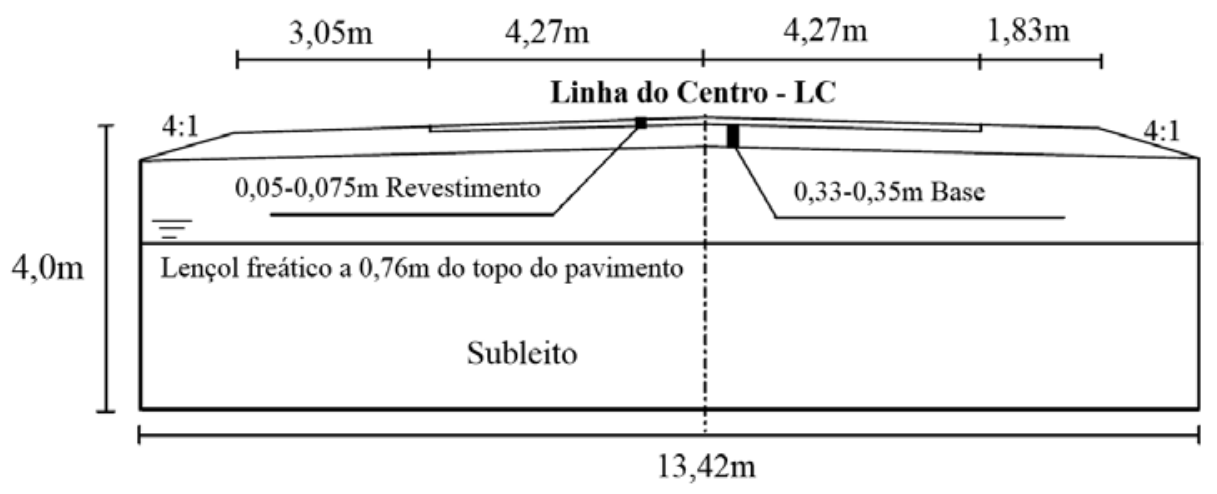

Figura 1. Seção transversal de pavimento asfáltico (Adaptada de Masad et al., 2002) 


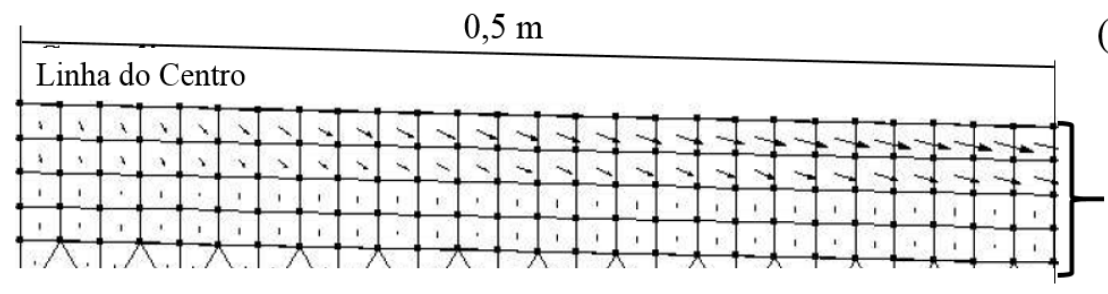

(k) das quatro subcamadas do revestimento $\mathrm{k}_{1}-3,84 \times 10^{-4} \mathrm{~m} / \mathrm{s}$ $\mathrm{k}_{2}-5,79 \times 10^{-5} \mathrm{~m} / \mathrm{s}$ $\mathrm{k}_{3}-5,48 \times 10^{-5} \mathrm{~m} / \mathrm{s}$ $\mathrm{k}_{4}-8,27 \times 10^{-5} \mathrm{~m} / \mathrm{s}$

Figura 2. Vetores de fluxo próximo da linha de centro do pavimento (Adaptada de Masad et al., 2002)

Onde: $\gamma=$ peso específico do fluido $\left(9,79 \mathrm{kN} / \mathrm{m}^{3}\right.$ para a água a $\left.20^{\circ} \mathrm{C}\right), \mu=$ viscosidade do fluido $\left(10^{-3} \mathrm{~kg} / \mathrm{m} . \mathrm{s}\right.$ para a água), $\mathrm{S}_{\mathrm{agg}}$ representa a área de superfície específica dos agregados, considerando que as partículas apresentam forma cúbica $(\mathrm{l} / \mathrm{m})$, e por fim, $c, m$ e $t$ são valores obtidos a partir da calibração do modelo.

A partir da distribuição interna dos vazios, obtida por meio de tomografia computadorizada, foi possível determinar o Vv médio a cada 10,4mm, iniciando a partir do topo do revestimento. A Figura 2 apresenta o padrão dos vetores obtidos no citado estudo, quando a seção hipotética é modelada simulando um evento de chuva. A precipitação pluviométrica utilizada foi obtida a partir de medidas reais. Cada subcamada do revestimento apresenta um $k$ diferente, obtido a partir da Equação 1.

Analisando a Figura 2, verifica-se que o fluxo horizontal é predominante nas duas subcamadas iniciais. Vale ressaltar que a permeabilidade da primeira subcamada é aproximadamente seis vezes maior do que a permeabilidade das outras subcamadas (Figura 2). Dessa forma, o fluxo horizontal foi observado, principalmente, na subcamada com maior permeabilidade, no topo do revestimento.

Diante dos resultados observados por Masad et al. (2002), verifica-se que o padrão de fluxo no revestimento está diretamente relacionado com a distribuição da permeabilidade na profundidade do revestimento. Como a permeabilidade é diretamente influenciada pela distribuição dos vazios interconectados, espera-se que quanto maior for a quantidade deles, maior seja também a permeabilidade do material.

Dessa forma, alguns autores, como Kutay et al. (2007), analisaram o padrão de fluxo em amostras cilíndricas de misturas asfálticas com aproximadamente $10 \mathrm{~cm}$ de altura, dividindo as mesmas em três partes: topo, meio e base. Nesse estudo, foram analisadas misturas asfálticas do tipo SMA (Stone Matrix Asphalt). A permeabilidade foi calculada analiticamente a partir da distribuição interna dos vazios. Para isso foram utilizadas técnicas de análise de imagens para observar o comportamento dos vazios com a profundidade da amostra. Para o SMA, a porosidade média

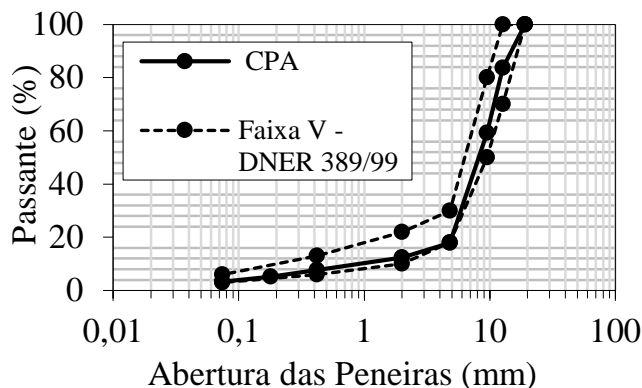

no topo e na base das amostras é de aproximadamente $17 \%$, enquanto que no meio da amostra este parâmetro é de aproximadamente $11 \%$. Dessa forma, os autores observaram que o fluxo d’água na direção horizontal é melhor observado no topo e na base da amostra, pois a maior parte dos poros interconectados se encontra nessas regiões. Já o fluxo vertical é mais observado na parte central da amostra, região com menor porosidade.

\section{MATERIAIS E MÉTODOS}

\subsection{Misturas Asfálticas}

As misturas asfálticas analisadas neste trabalho foram compostas por britas de $3 / 4$ " e de $1 / 2$ " como agregado graúdo, e pó de pedra e areia de campo como agregados miúdos. Para a CPA, além dos agregados citados, foi utilizada a cal como material de enchimento (fíler). A Figura 3 apresenta as curvas granulométricas das misturas asfálticas avaliadas.

Os três tipos de misturas asfálticas (CA, AA e CPA) avaliadas foram dosadas seguindo a metodologia Superpave. O ligante asfáltico utilizado nas misturas asfálticas CA e AA foi classificado por penetração como CAP 50/70. Para a mistura asfáltica do tipo CPA, também foi utilizado o mesmo ligante (CAP 50/70), porém modificado com $4 \%$ em massa do polímero SBS. O SBS utilizado era do tipo D 1192 BT, fornecido pela empresa Kraton Polímeros. A Tabela 1 apresenta um resumo dos valores (médias) dos parâmetros de dosagem obtidos a partir de três amostras para cada mistura asfáltica avaliada. Também são apresentados na Tabela 1 os resultados de permeabilidade obtidos por Ferreira (2013) e de desgaste Cântabro para a mistura asfáltica do tipo CPA. De acordo com a DNER 386/99, misturas asfálticas do tipo CPA devem apresentar desgaste Cântabro equivalente a, no máximo, $25 \%$.

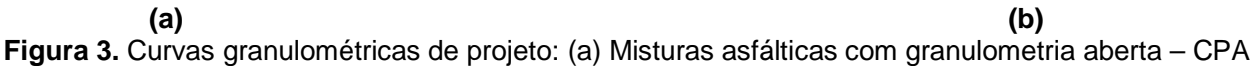
e (b) Misturas asfálticas com granulometria densa - AA e CA
} 
Tabela 1. Parâmetros de dosagem das misturas asfálticas investigadas

\begin{tabular}{|c|c|c|c|c|c|c|c|c|}
\hline Mistura Asfáltica & $\begin{array}{l}\text { CAP } \\
\text { (\%) }\end{array}$ & $\mathbf{G}_{\mathbf{m m}}$ & $\mathbf{G}_{\mathbf{m b}}$ & $\mathbf{N}^{\circ}$ Giros & $\begin{array}{l}\text { RBV } \\
\text { (\%) }\end{array}$ & $\begin{array}{l}\text { Vv } \\
(\%)\end{array}$ & $\begin{array}{c}\mathbf{k} \\
(\mathbf{m} / \mathbf{s})\end{array}$ & $\begin{array}{c}\text { Cântabro } \\
\text { (\%) }\end{array}$ \\
\hline \multirow{2}{*}{ CA } & \multirow{2}{*}{5,0} & \multirow{2}{*}{2,447} & 2,349 & 100 & 74,1 & 4,0 & $8,81 \times 10^{-7}$ & - \\
\hline & & & 2,284 & 30 & 62,0 & 7,0 & $3,80 \times 10^{-6}$ & - \\
\hline \multirow{2}{*}{ AA } & \multirow{2}{*}{6,5} & \multirow{2}{*}{2,383} & 2,203 & 100 & 65,2 & 7,0 & $1,99 \times 10^{-7}$ & - \\
\hline & & & 2,160 & 30 & 59,2 & 9,0 & $2,64 \times 10^{-7}$ & - \\
\hline \multirow{2}{*}{ CPA } & 4,0 (modificado com & \multirow{2}{*}{2,463} & 1,976 & 50 & 28,0 & 20,0 & $1,06 \times 10^{-4}$ & 17,0 \\
\hline & $4 \%$ de SBS em massa) & & 1,922 & 30 & 25,0 & 23,0 & $1,24 \times 10^{-4}$ & 19,0 \\
\hline
\end{tabular}

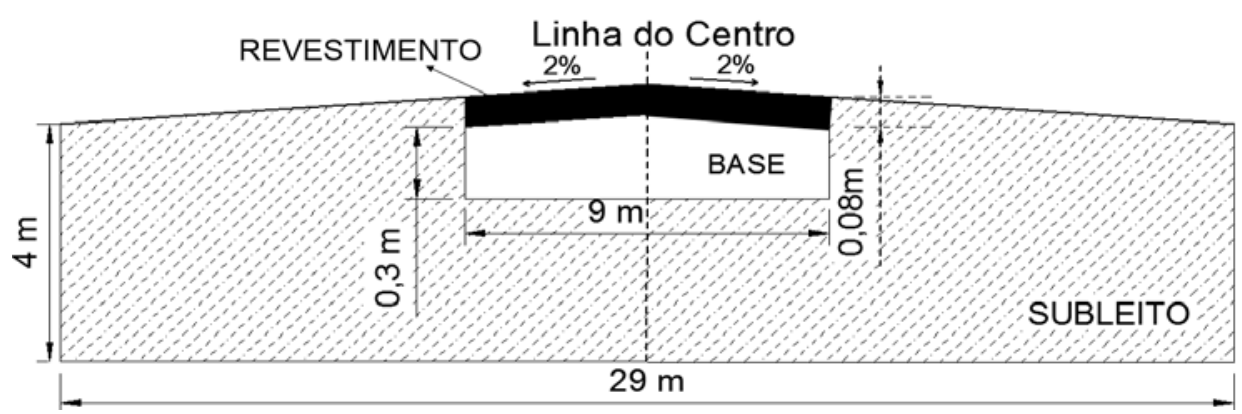

Figura 4. Ilustração da situação hipotética analisada (sem escala)

\subsection{Seção Hipotética Avaliada}

O fluxo d’água no pavimento foi modelado utilizando a seção transversal de um pavimento asfáltico típico, como apresentando na Figura 4. As permeabilidades para as camadas de base e para o subleito foram mantidas constantes, e assumidas como as mesmas utilizadas por Masad et al. (2002). A base considerada tem permeabilidade saturada igual a $1,54 \times 10^{-6} \mathrm{~m} / \mathrm{s}$ e o subleito igual a $2,75 \times 10^{-8} \mathrm{~m} / \mathrm{s}$. Segundo os autores, a base representa uma mistura de solo com agregado granítico e o subleito representa um solo argiloso siltoso. Para o revestimento asfáltico foram adotados os valores de permeabilidade obtidos por Ferreira (2013). O subleito teve a lateral prolongada em $10 \mathrm{~m}$ para cada lado, com o objetivo de ser mais condizente com o que ocorre em campo.

É importante ressaltar que seria interessante utilizar valores de permeabilidade da camada de base e do subleito de materiais típicos brasileiros, pois os materiais considerados por Masad et al. (2002) podem ser diferentes dos solos usualmente utilizados no Brasil em serviços de pavimentação. Tal fato pode influenciar a análise realizada no presente estudo. Além disso, espessuras diferentes para as camadas do pavimento, bem como o nível do lençol freático, também podem influenciar o comportamento do fluxo d'água no sistema.

\subsection{Utilização do Programa Slide 6.0}

O programa Slide 6.0 foi utilizado para realizar a análise de fluxo. Esse programa, baseado no MEF, é um dos mais abrangentes e disponíveis para realizar análises de estabilidade de taludes, infiltração, fluxo e outros, em materiais porosos. Na Figura 5 pode-se verificar, a título de exemplo, uma malha gerada no programa. A malha de elementos finitos utilizada incluiu 12.000 elementos triangulares. Fluxos, pressões e gradientes são calculados com base nas condições de contorno hidráulicas que o usuário define.

Com relação às condições de contorno, foi verificada na literatura a altura da lâmina d’água em pavimentos de acordo com a intensidade da chuva. Prado e Palma (2012) determinaram uma metodologia analítica para determinação da lâmina d’água em pavimentos aeroportuários, pois, assim como em rodovias, a formação de lâmina d'água pode gerar problemas funcionais, como o fenômeno da hidroplanagem. No citado trabalho, a lâmina d'água no pavimento foi determinada a partir de diversos valores de intensidade de chuva, variando de 5 a $100 \mathrm{~mm} / \mathrm{h}$, para um pavimento com declividade igual a 1,5\%. A International Civil Aviation Organization - ICAO (2002) afirma que é necessária a manutenção dos pavimentos quando a lâmina d’água for superior a 3mm. Entretanto, a espessura da lâmina d’água vai depender de diversos fatores, como a declividade da pista, a macrotextura, a intensidade da chuva, dentre outros. No entanto, de acordo com o observado por Prado e Palma (2012), somente com uma chuva muito intensa $(100 \mathrm{~mm} / \mathrm{h})$ será possível atingir uma lâmina d’água de 3mm ou superior. Dessa forma, no presente trabalho foi considerado o caso crítico, com uma lâmina d’água igual a 3mm mantida constante sobre a superfície do pavimento, isto é, quando ocorre uma chuva intensa de 100mm durante uma hora.

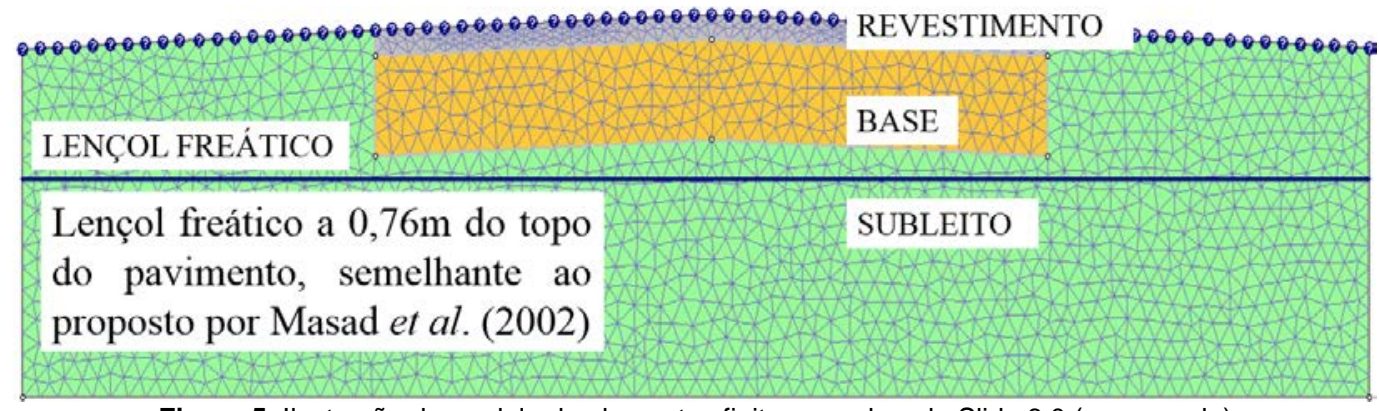

Figura 5. Ilustração do modelo de elementos finitos gerado pelo Slide 6.0 (sem escala) 
Foi realizada uma análise transiente para verificar o comportamento do sistema com o tempo. Os casos de fluxo denominados transientes indicam que a quantidade de água que passa através de uma superfície de um elemento varia com o tempo (Freeze e Cherry, 1979). Dessa forma, para chuvas intensas com uma hora de duração, o tempo foi dividido em cinco estágios (10, 20, 30, 40 e 60 minutos). Em cada estágio, é possível verificar o comportamento do sistema quando uma lâmina d'água de $3 \mathrm{~mm}$ de espessura é mantida constante sobre a superfície do pavimento.

\section{RESULTADOS E DISCUSSÕES}

\subsection{Mistura Asfáltica do Tipo CA}

Para que o fluxo ocorra de um ponto para outro é necessário que haja uma diferença positiva entre a carga total dos dois pontos. A carga total é a soma de duas parcelas: carga altimétrica e carga piezométrica. A carga altimétrica é a diferença entre o ponto considerado e qualquer cota definida como de referência. A carga piezométrica é a pressão d'água no ponto, expressa em altura de coluna d’água (Pinto, 2002). Dessa forma, foi analisada a carga total na superfície do revestimento e na interseção do revestimento com a base do pavimento, de modo a observar se o padrão de fluxo é horizontal e/ou vertical. As Figuras 6a e 6b apresentam o comportamento da carga total a partir do afastamento da linha do centro do pavimento para as duas misturas asfálticas do tipo CA avaliadas.
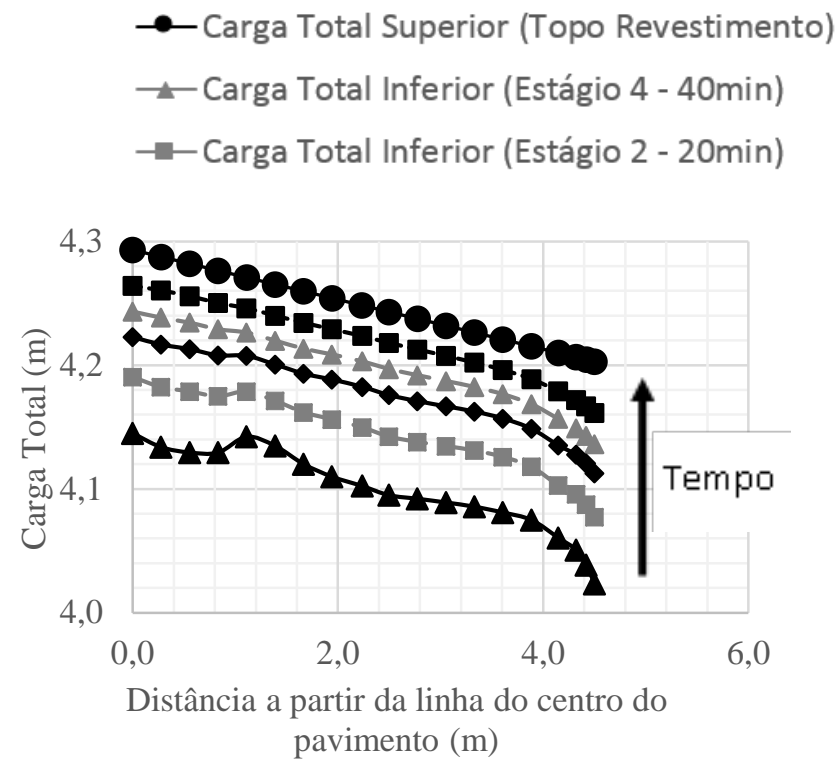

(a) $\mathrm{CA}-4 \%$ de $\mathrm{Vv}$

Figura 6. Variação da carga total a partir da litro do pavimento para as duas misturas asfálticas do tipo CA analisadas
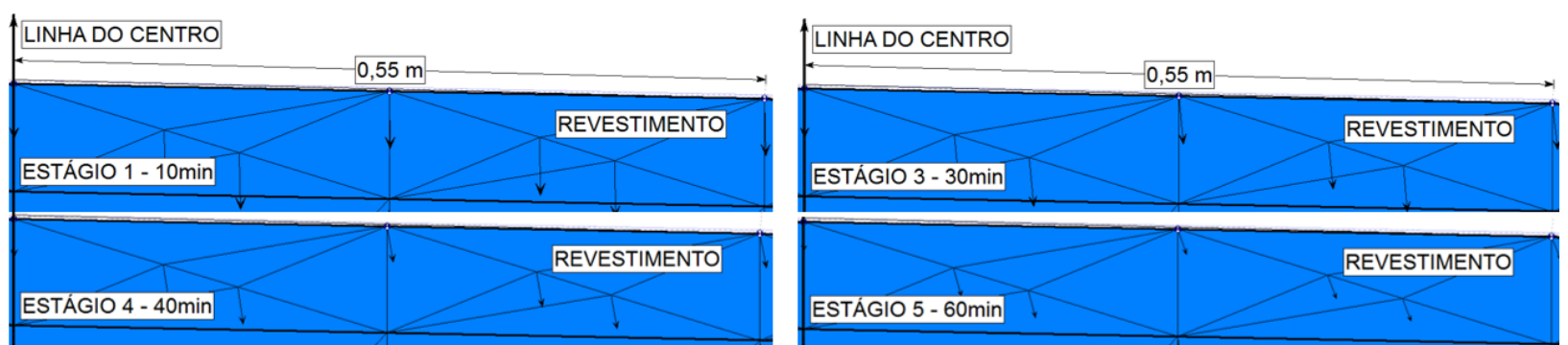

Figura 7. Comportamento dos vetores de fluxo próximos a linha de centro do pavimento para a mistura asfáltica do tipo CA com $7 \%$ de $\mathrm{VV}$ 68

TRANSPORTES v. 23, n. 2 (2015), p.64-72 topo do revestimento (superior) e na base do mesmo (inferior), maior deve ser a quantidade de água fluindo na direção vertical. Na Figura 6a, verifica-se que, com o tempo, essa diferença entre a carga total nos dois pontos diminui.

No estágio 1 (10min), a diferença média entre os pontos (topo e base) é de $0,15 \mathrm{~m}$. Já no estágio 5 (60min), essa diferença média é de $0,03 \mathrm{~m}$. Portanto, houve uma redução de $80 \%$ na diferença entre as cargas totais. Essa diferença tende a diminuir com o tempo, pois com uma lâmina d'água constante sobre a superfície do revestimento, o grau de saturação no interior do material tende a aumentar, e, como consequência, o fluxo na direção vertical tende a diminuir e o fluxo na direção horizontal tende a crescer.

Para a mistura asfáltica do tipo CA com $7 \%$ de Vv, o comportamento da variação da carga total com o tempo é semelhante ao observado para a mistura asfáltica do tipo CA com $4 \%$ de Vv, como pode ser observado na Figura $6 \mathrm{~b}$. Entretanto, para a mistura asfáltica com $7 \%$ de Vv, verificase que a diferença entre a carga total no topo do revestimento e na parte inferior do mesmo é menor do que o que foi observado para a mistura asfáltica com $4 \%$ de Vv. Esse comportamento é justificado pela permeabilidade do material, pois a mistura asfáltica com 7\% de Vv apresenta maior permeabilidade (quatro vezes maior), portanto, a quantidade de água contida na camada tende a aumentar mais rapidamente. Quanto maior for a permeabilidade do material, menor deverá ser o tempo necessário para que o grau de saturação da camada aumente. Para a mistura asfáltica com maior permeabilidade (CA com 7\% de Vv), para o último

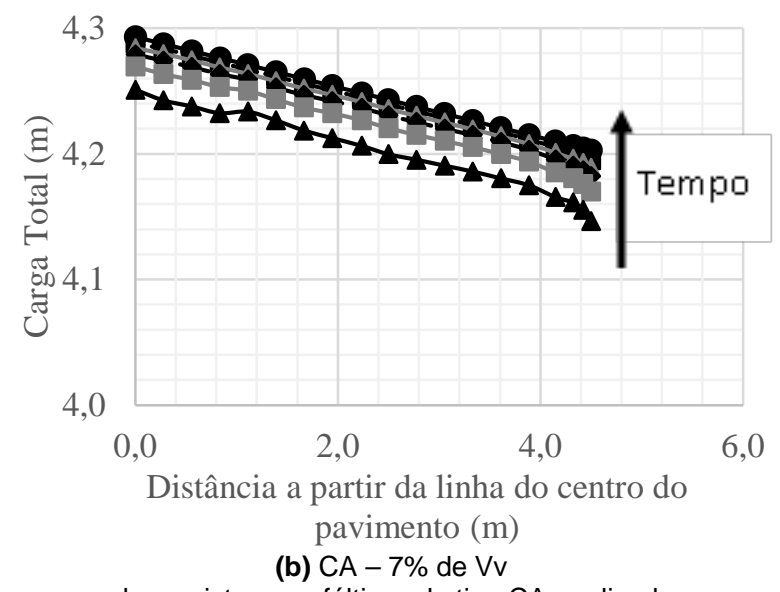


estágio avaliado (estágio 5), verificou-se que a diferença média entre a carga total para pontos na horizontal (a partir da linha do centro até o final do revestimento) é maior (25\%) do que a diferença média entre os pontos na vertical (topo e base do revestimento). Como consequência, começa a surgir fluxo na direção horizontal. Na Figura 7 pode-se observar o comportamento dos vetores de fluxo próximo à linha do centro para a mistura asfáltica do tipo CA com 7\% de Vv.

Observando a Figura 7, verifica-se que o comportamento dos vetores corrobora com a avaliação feita anteriormente a partir da análise da variação da carga total. Com o tempo, os tamanhos dos vetores na vertical tendem a diminuir e o fluxo horizontal começa a surgir lentamente. Para as análises apresentadas anteriormente, foi considerado que a permeabilidade horizontal é igual a vertical. Entretanto, é importante salientar que misturas asfálticas são materiais anisotrópicos (Zhang et al., 2012), portanto, podem apresentar comportamento diferente nas direções vertical e horizontal. Al Omari (2004) analisou a permeabilidade horizontal e vertical de diferentes tipos de misturas asfálticas; e afirmou que, para misturas asfálticas com granulometria densa, a razão entre a permeabilidade horizontal e a vertical está entre 8,35 e 11,40. Já para misturas asfálticas com granulometria aberta, esse intervalo varia de 1,65 a 4,02. Acredita-se que a permeabilidade horizontal deva ser maior do que a permeabilidade vertical também para as misturas asfálticas avaliadas nesse trabalho.

Para avaliar a condição anisotrópica de misturas asfálticas do tipo CA, foi simulado o comportamento do revestimento quando a permeabilidade horizontal $\left(k_{h}\right)$ é dez vezes maior do que a permeabilidade vertical $\left(k_{v}\right)$. Esse valor foi adotado, pois está dentro do intervalo $(8,35$ - 11,40) obtido por Al Omari (2004) para misturas asfálticas com granulometria densa. A Figura 8 apresenta o comportamento dos vetores de fluxo próximo da linha do centro do pavimento para a situação inicialmente avaliada $\left(k_{h} / k_{v}=1\right)$ e para a condição anisotrópica do material $\left(k_{h} / k_{v}=10\right)$.

Analisando a Figura 8, observa-se que para a situação 1 (condição isotrópica) o fluxo vertical é predominante, mesmo no estágio 5 (60min). Já para condição anisotrópica (situação 2), verifica-se que depois do estágio 3 (30min) o fluxo horizontal começa a ser visualizado. Comparando a situação 1 (isotrópica) com a situação 2 (anisotrópica), no geral, houve uma pequena redução, em média de 3\%, na diferença entre a carga total no topo e na base do revestimento. Essa pequena redução na diferença entre as cargas totais foi suficiente para modificar o comportamento dos vetores no estágio 5 (60min). Dessa forma, verificou-se que mesmo considerando a permeabilidade horizontal como dez vezes maior do que a permeabilidade vertical, o fluxo na direção vertical continua predominante. Entretanto, observou-se que na condição anisotrópica, o sistema tende a aumentar o grau de saturação em um menor tempo, pois nessa situação a permeabilidade na direção horizontal é maior, como consequência, a quantidade de água dentro do sistema aumenta em um tempo menor. Desse modo, o fluxo na direção horizontal surge antes do que surgiria se a camada fosse considerada isotrópica, como se pode constatar na Figura 8 .

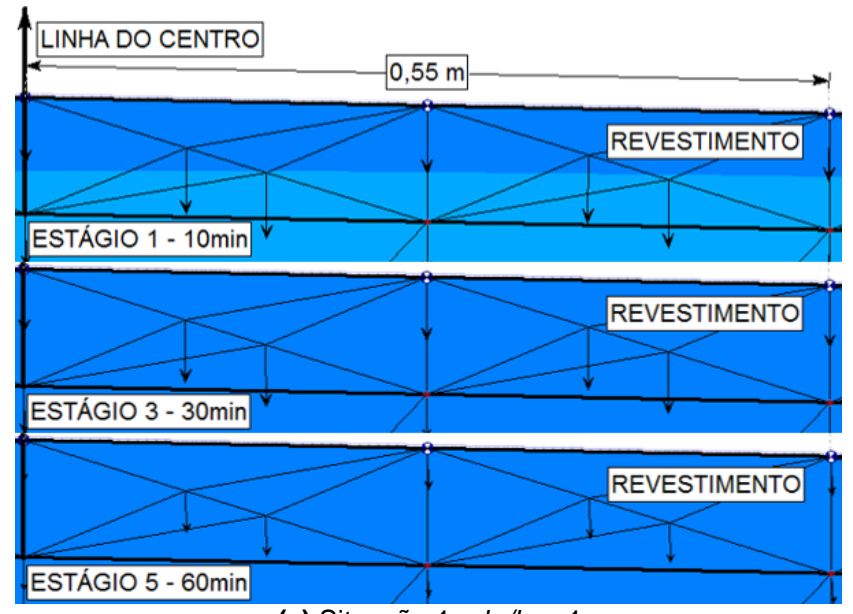

(a) Situação $1-k_{h} / k_{v}=1$

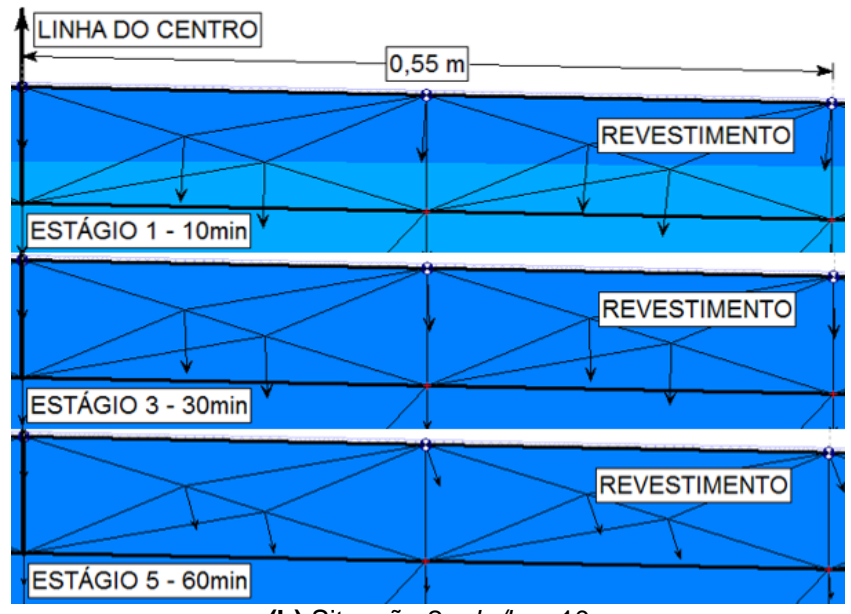

(b) Situação $2-k_{h} / k_{v}=10$

Figura 8. Comportamento dos vetores de fluxo próximo da linha do centro para a mistura asfáltica do tipo CA com $4 \%$ de $V v$

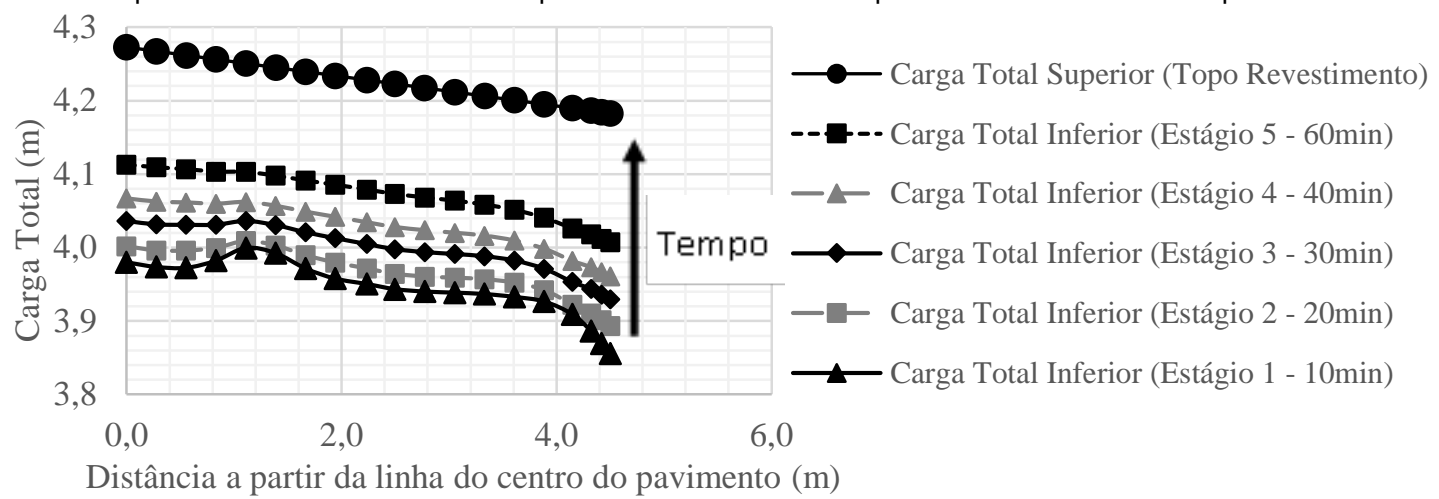

Figura 9. Variação da carga total a partir da linha de centro do pavimento para a mistura asfáltica do tipo AA com $7 \%$ de $\mathrm{VV}$ 


\subsection{Mistura Asfáltica do Tipo AA}

A análise de fluxo para a mistura asfáltica do tipo AA para os dois Vv estudados foi semelhante, pois a permeabilidade é praticamente a mesma para os dois casos estudados, como pode ser observado na Tabela 1. A Figura 9 apresenta os resultados obtidos para a mistura asfáltica do tipo AA com $7 \%$ de $\mathrm{Vv}$.

Na Figura 9, verifica-se que o comportamento é o mesmo observado anteriormente. A medida que o tempo aumenta, a diferença entre a carga total no topo e na base do revestimento diminui, isto é, a quantidade de água fluindo verticalmente diminui com o tempo. A ordem de grandeza da permeabilidade para a mistura do tipo AA, considerando os dois $\mathrm{Vv}$ avaliados, é a mesma observada para a mistura do tipo o CA com $4 \%$ de Vv. Apesar de possuir a mesma ordem de grandeza $\left(10^{-7} \mathrm{~m} / \mathrm{s}\right)$, a mistura AA apresenta permeabilidade menor (aproximadamente quatro vezes menor), se comparada ao valor encontrado para a mistura CA com $4 \%$ de $\mathrm{Vv}$.

Além disso, analisando os resultados apresentados nas Figuras 9 e 6a, observa-se que a diferença entre a carga total inferior no último estágio avaliado (estágio 5 - 60min) e no topo do revestimento é maior para a mistura AA (mistura asfáltica com menor permeabilidade). Isto significa que a baixa permeabilidade faz com que o material demore mais para saturar, tornando o fluxo vertical predominante por um maior tempo. Do contrário, um material com permeabilidade maior precisa de um menor tempo para saturar. Quando o material começa a saturar, o fluxo horizontal começa a ser observado. Dessa forma, na situação inicialmente avaliada (condição isotrópica), para as misturas asfálticas com baixa permeabilidade (AA e CA), o fluxo na direção horizontal somente será observado com um tempo superior a 60min. Já para as misturas asfálticas com elevada permeabilidade, caso das misturas asfálticas com granulometria aberta, o comportamento é diferente, como será abordado adiante.

A condição anisotrópica também foi simulada para a mistura asfáltica do tipo AA considerando o mesmo caso analisado anteriormente $\left(k_{h} / k_{v}=10\right)$. Para esse tipo de mistura asfáltica, não foi observado fluxo na direção horizontal mesmo no estágio 5 (60min). Dessa forma, para verificar a partir de que momento o fluxo na direção horizontal começa a surgir, foram testados outros estágios (200, 300 e $400 \mathrm{~min}$ ). Verificou-se que para a mistura AA, mesmo considerando a permeabilidade horizontal como dez vezes maior, o fluxo na direção horizontal somente tende a surgir depois de 300min, isto é, o material tende a saturar depois de 300min. Além disso, foram testados outros valores da relação entre as permeabilidades horizontal e vertical. Foi observado que quando essa relação é acima de 50, o fluxo na direção horizontal surge antes, a partir de $100 \mathrm{~min}$.

\subsection{Mistura Asfáltica do Tipo CPA}

Para analisar o fluxo no revestimento composto por CPA, a espessura desta camada foi modificada. Considerou-se um revestimento com espessura igual a $10 \mathrm{~cm}$, sendo 4cm de CPA e 6cm de CA, pois quando utilizam-se misturas asfálticas do tipo CPA, é necessária a utilização de uma camada abaixo da mesma com uma permeabilidade inferior. Em termos de dados de entrada no programa, foi utilizada a permeabilidade da mistura CA com $4 \%$ de Vv. Já para a mistura CPA foi utilizado o valor de permeabilidade obtido para o Vv de 20\%. Para a mistura asfáltica do tipo CPA com Vv de 23\% não serão apresentados os resultados neste trabalho, pois estes foram semelhantes aos observados para mistura asfáltica com Vv de $20 \%$.

Para avaliar o comportamento da carga total na camada de revestimento, diferentemente dos dois casos apresentados anteriormente, será observada a carga total no topo do revestimento (sobre a superfície da CPA), no encontro da CPA com o CA e no fim do revestimento (base do CA). Vale ressaltar que a principal função da CPA é retirar o excesso de água proveniente da chuva da superfície do pavimento. Dessa forma, o objetivo da CPA é justamente eliminar a lâmina d’água da superfície do pavimento. A Figura 10 apresenta o comportamento da carga total nos três segmentos analisados para os estágios 1 (10min) e 5 (60min). Observa-se na Figura 10 que a carga total no topo do revestimento e na intersecção da CPA com o CA é praticamente a mesma, tanto no estágio 1 quanto no estágio 5. Isto significa que a maior parte da água já está fluindo horizontalmente com apenas 10 min.

Dessa forma, verifica-se claramente que a CPA realiza sua principal função de coletar a água e rapidamente escoar lateralmente a mesma para o sistema de drenagem do pavimento. A condição anisotrópica também foi simulada no revestimento composto por CPA. A razão entre as permeabilidades horizontal e vertical foi considerada igual a três para a subcamada de CPA. Já para a subcamada de CA, que se encontra abaixo da CPA, a razão considerada foi igual a dez. A Figura 11 apresenta o comportamento dos vetores de fluxo próximo a linha de centro do pavimento para a situação inicialmente avaliada $\left(k_{h} / k_{v}=1\right)$ e para a

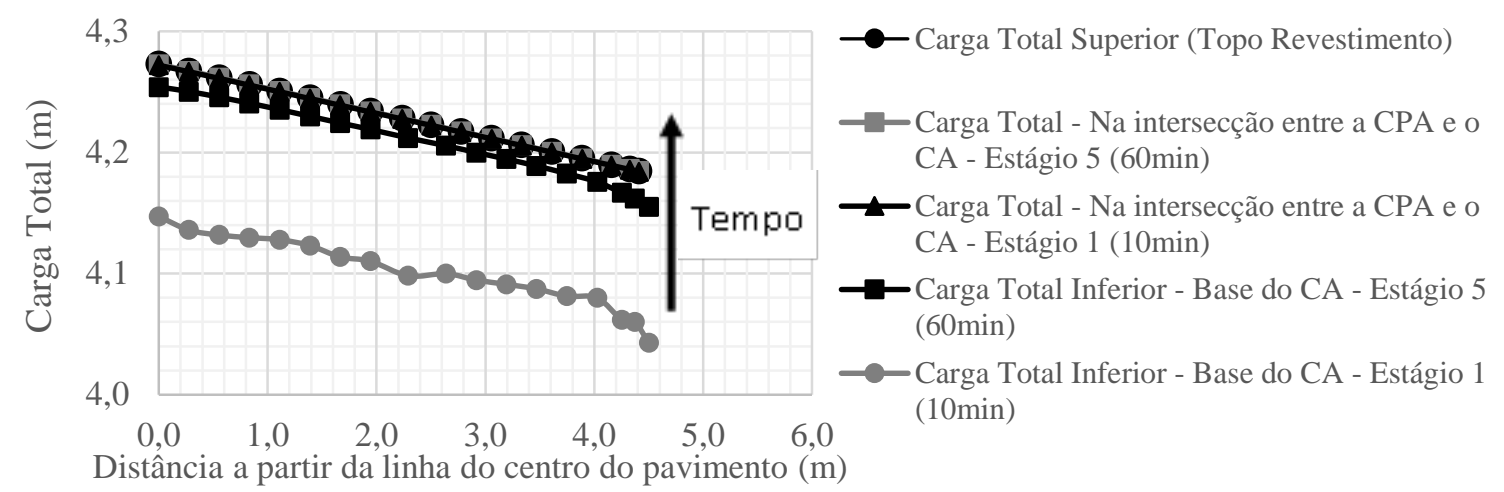

Figura 10. Variação da carga total a partir da linha de centro do pavimento para a mistura asfáltica do tipo CPA com 20\% de Vv - Estágio 1 (10min) e 5 (60min) 


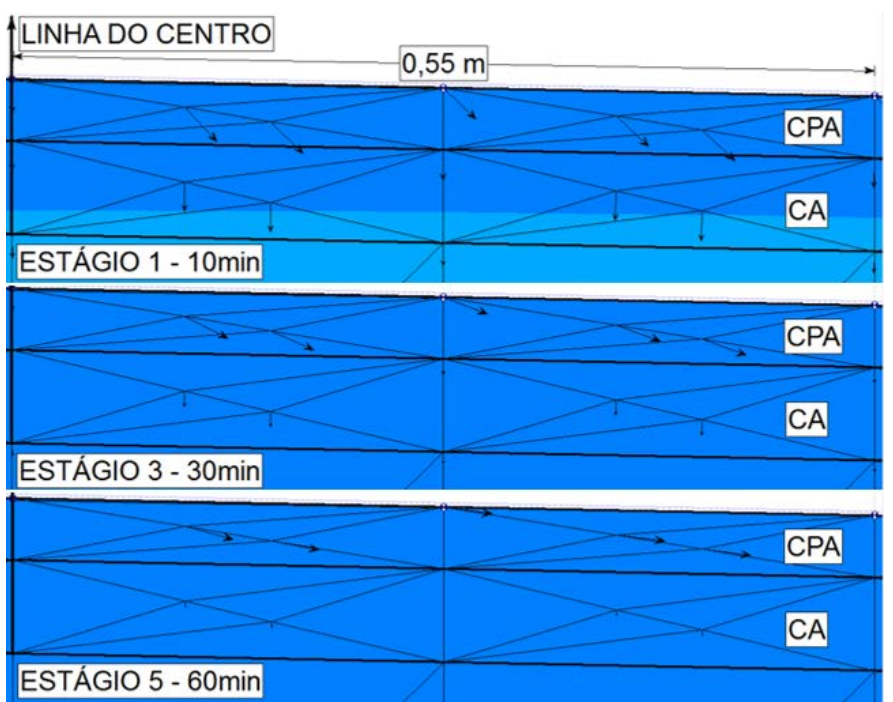

(a) Situação $1-k_{h} / k_{v}=1$

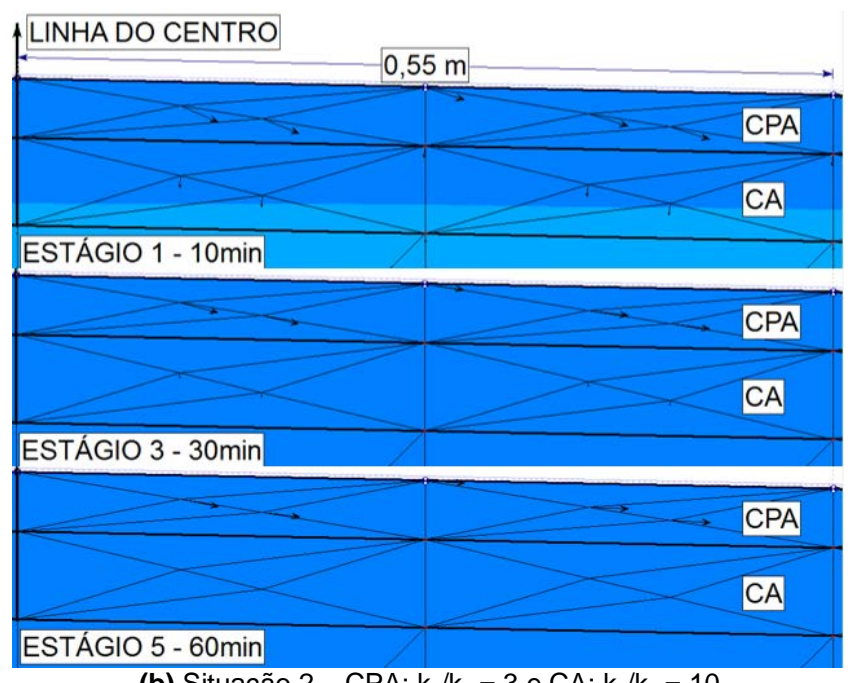

(b) Situação 2 - CPA: $k_{h} / k_{v}=3$ e CA: $k_{h} / k_{v}=10$

Figura 11. Comportamento dos vetores de fluxo próximo da linha do centro para um revestimento composto por uma subcamada de CPA (20\% de Vv), e por uma subcamada de CA ( $4 \%$ de Vv)

condição anisotrópica do material (CPA: $k_{h} / k_{v}=3$ e CA: $\left.k_{h} / k_{v}=10\right)$.

O valor da razão igual a três para a mistura asfáltica do tipo CPA foi adotada, pois está dentro do intervalo (1,65 - 4,02) obtido por Al Omari (2004) para misturas asfálticas com granulometria aberta. Dessa forma, analisando os resultados apresentados na Figura 11, observa-se, tanto para a situação 1 quanto para a situação 2, que o tamanho dos vetores na subcamada de CPA é praticamente o mesmo em todos os estágios avaliados, isto é, o fluxo horizontal é praticamente constante nessa camada. Já no CA, os vetores indicam fluxo vertical, que diminui de intensidade com o tempo. Dessa forma, observam-se padrões de fluxo diferentes dentro da camada de revestimento. Na subcamada de CPA o fluxo é horizontal, enquanto na subcamada de CA o fluxo é vertical. Na condição anisotrópica, o fluxo na direção vertical na subcamada de CA tende a desaparecer, isto é, a maior parte do fluxo na camada de revestimento passa a acontecer totalmente na direção horizontal dentro da subcamada de CPA.

A variação da permeabilidade dentro do revestimento, a partir de uma subcamada com maior permeabilidade na superfície (CPA) até uma camada de menor permeabilidade (CA), força o aparecimento do fluxo horizontal na parte mais permeável do revestimento. Esse comportamento observado na mistura de CPA indica que, para compreender o padrão de fluxo no interior do revestimento, é necessário verificar como a permeabilidade está distribuída nessa camada. Dessa forma, se o revestimento apresenta permeabilidade diferente no topo, no meio e na base, o padrão de fluxo será diferente caso seja considerada apenas a permeabilidade média do material.

\section{CONCLUSÕES}

No presente trabalho, foi utilizado o programa Slide 6.0, comumente usado para a análise de percolação em materiais granulares, com o objetivo de realizar estudos de fluxo em uma seção hipotética de um pavimento asfáltico. A seção hipotética e as características dos materiais de base e do subleito foram mantidas constantes. A partir de dife- rentes tipos de revestimentos, foi observado o comportamento do padrão de fluxo, mantendo-se uma lâmina d’água de $3 \mathrm{~mm}$ sobre a superfície do revestimento. Observou-se que quanto maior a permeabilidade do revestimento, maior também deverá ser o fluxo na direção horizontal. Materiais com baixa permeabilidade (misturas asfálticas do tipo CA e AA) apresentaram fluxo na direção horizontal depois de um dado tempo (no mínimo acima de 60min para os casos em estudo), pois o grau de saturação na camada aumenta. Nesse ponto, o fluxo horizontal tende a surgir. Para o caso da mistura asfáltica aberta do tipo CPA, o revestimento foi dividido em uma camada de $4 \mathrm{~cm}$ de CPA e outra camada de $6 \mathrm{~cm}$ de CA. O resultado dessa análise serviu para constatar que o padrão de fluxo no revestimento depende não somente da média da permeabilidade, mas também de como a permeabilidade está distribuída nas diversas partes da camada, como, por exemplo, no topo, no meio e na base do revestimento. Dessa forma, para entender como ocorre o padrão de fluxo no material, é importante compreender como a permeabilidade pode estar variando nas diversas partes do mesmo. Nesse contexto, como a permeabilidade é diretamente influenciada pela distribuição dos vazios interconectados, entender como esses vazios estão distribuídos pode ajudar a compreender o padrão de fluxo no interior do material. Quando a condição anisotrópica foi simulada, verificou-se que o fato da permeabilidade horizontal ser maior do que a permeabilidade vertical contribuiu para aumentar o grau de saturação da camada em um menor tempo, pois, nessa situação a água terá maior facilidade de fluir na direção horizontal. Desse modo, foi observado que a componente horizontal do fluxo surge antes do que surgiria se a camada fosse considerada isotrópica.

Diante dos resultados obtidos no presente estudo, sugere-se determinar o $k$ de uma camada de revestimento em três partes: no topo, no meio e na base. Além disso, seria interessante obter o $k$ horizontal dos materiais estudados nessa pesquisa, pois todas as análises da condição anisotrópica foram realizadas considerando valores encontrados na literatura. Sugere-se também utilizar valores de permeabilidade na camada de base e no subleito de materiais tipicamente brasileiros. Por fim, sugere-se tentar correlacionar o 
padrão de fluxo com o dano por umidade no material e verificar como a presença da lâmina d'água (e a consequente eliminação da mesma) pode afetar a segurança viária.

\section{AGRADECIMENTOS}

Os autores agradecem ao Laboratório de Mecânica dos Pavimentos (LMP/DET/UFC) pelo apoio operacional concedido e ao CNPq pelas bolsas concedidas ao primeiro e ao segundo autores. Além disso, os autores agradecem ao grupo de Geotecnica do Departamento de Engenharia Hidráulica e Ambiental (DEHA/UFC) pelo fornecimento da licença para utilização do programa Slide 6.0.

\section{REFERÊNCIAS}

Al Omari, A.A.M. (2004) Analysis of HMA Permeability through Microstructure Characterization and Simulation of Fluid Flow in $X$-ray CT Images. Tese de Doutorado, Texas A\&M University, Texas. Disponível em: <http://faculty.ksu.edu.sa/aslam/ Aslam\%20Documents/PhD.pdf $>$.

Chaves, F.J. (2010) Estudo de Misturas de Areia Asfalto a Frio em Pavimentação de Baixo Volume de Tráfego no Estado do Ceará - Contribuição ao Método de Dosagem. Tese (Doutorado)- COPPE, Universidade Federal do Rio de Janeiro, Rio de Janeiro, RJ. Disponível em: http://docplayer.com.br/5377976-

Estudo-de-misturas-de-areia-asfalto-a-frio-em-pavimentacao-debaixo-volume-de-trafego-no-estado-do-ceara-contribuicao-aometodo-de-dosagem.html>.

DNER-ES 386 (1999) Departamento Nacional de Estradas de Rodagem. Pavimentação: Pré-Mistura a Quente com Asfalto Polímero: Camada Porosa de Atrito. Rio de Janeiro, RJ, Brasil.

Ellis, W.H.; Schmidt, R.J. (1960) A Method for Measuring the Air Permeabilities of Asphalt Concrete Pavements. Road and Paving Session, ASTM, Atlantic City, New Jersey DOI: 10.1520/STP46391S.

Falcão, P.R.F. (2007) Estudo das Propriedades Mecânicas e Hidráulicas de Concretos Asfálticos para Aplicação em Barragens. Tese (Doutorado)- Departamento de Engenharia Civil e Ambiental, Universidade de Brasília - UNB, Brasília, DF. Disponível em: <http://www.researchgate.net/publication /43978780_Estudo_das_propriedades_mecnicas_e_hidrulicas_de _concretos_asflticos_para_aplicao_em_barragens>.

Ferreira, W.L.G. (2013) Avaliação da Permeabilidade de Misturas Asfálticas com Diferentes Granulometrias. Monografia. Universidade Federal do Ceará, Fortaleza, CE

Ferreira, W.L.G e Castelo Branco, V.T.F. (2014) Avaliação da Permeabilidade de Misturas Asfálticas com Diferentes Granulometrias. $43^{a}$ Reunião Anual de Pavimentação - RAPv, Maceió/AL, Brasil.

Freeze, R.A., Cherry, J.A. (1979) Groundwater. 3. ed. London, UK : Prentice Hall.

Guimarães, R.C. (2012) Barragens com Núcleo de Concreto Asfáltico: Análise do Comportamento Mecânico e Hidráulico do Núcleo. Tese (Doutorado)- Departamento de Engenharia Civil e Ambiental, Universidade de Brasília - UNB, Brasília, DF.
International Civil Aviation Organization (2002). Airport Service Manual: Pavement Surface Conditions (DOC 9132, part 2.) 4. ed. Montreal: ICAO.

Kutay, M.E, Aydilek, A.H., Masad, E. (2007) Estimation of Directional Permeability of HMA Based on Numerical Simulation of Micro-scale Water Flow. Transportation Research Record: Journal of Transportation Research Board, n. 2001, p. 29-36, Washington, D.C. DOI: 10.3141/2001-04.

Masad, E.; Birgisson, B.; Al Omari, A.; Cooley, A. (2002). Analysis of Permeability and Fluid Flow in Asphalt Mixes. In: 82th Annual Meeting Transportation Research Board, USA.

Nascimento, R.R. (2005) Utilização de Agregados de Argila Calcinada em Pavimentação: uma Alternativa para o Estado do Acre. Dissertação (Mestrado). Universidade Federal do Rio de Janeiro, Rio de Janeiro, RJ. Disponível em: <http://wwwp.coc. ufrj.br/teses/mestrado/geotecnia/2005/Teses/NASCIMENTO_R R_05_t_M_geo.pdf >.

Oliveira, C.G.M. (2003) Estudos de Propriedades Mecânicas e Hidráulicas do Concreto Asfáltico Drenante. Dissertação (Mestrado)- Universidade de Brasília, Distrito Federal, DF.

Pinto, C.S. (2002) Curso Básico de Mecânica dos Solos em 16 Aulas. 2. ed., São Paulo, SP : Oficina de Textos.

Prado, L.A.; Palma, G. (2012) Metodologia Analítica para Estimativa da Lamina D’Água em Pavimentos Aeroportuários. Revista Conexão SIPAER, n. 2, v. 3, p. 38-65, Brasília, D.F. ISSN 2176-7777.

Souza, S.A. (2008) Avaliação da Capacidade de Escoamento da Água em Mistura Asfáltica Drenante: proposta de ensaio de laboratório. Dissertação (Mestrado) - Universidade Federal do Rio de Janeiro, Rio de janeiro, RJ. Disponível em: $<$ http://wwwp.coc.ufrj.br/teses/mestrado/geotecnia/2008/Teses/S OUZA_SA_08_t_M_geo.pdf $>$

Zhang, Y.; Luo, R.; Lytton, R. (2012) Anisotropic Viscoelastic Properties of Undamaged Asphalt Mixtures. Journal of Transportation Engineering, v. 138, n. 1, p. 75-89. DOI: 10.1061/ (ASCE) TE. 1943-5436. 0000302. 